\title{
Axotomy-induced Changes in Rabbit Hindlimb Nerves and the Effects of Chronic Electrical Stimulation
}

\author{
Tessa Gordon, Jean Gillespie, Roberto Orozco, ${ }^{\mathrm{a}}$ and Lyle Davis \\ Department of Pharmacology and Division of Neuroscience, University of Alberta, Edmonton, Alberta, Canada T6G 2S2
}

\begin{abstract}
Chronic electrical stimulation and extracellular recording combined with morphological examination of nerves in this study provided a detailed description of the time course and extent of fiber atrophy when the trophic influence of the target was removed by ligation of axotomized nerves and neural activity was replaced by chronic stimulation. The major findings are that decline in amplitude of compound action potentials (CAPs) and fiber diameters is rapid after axotomy and is not reversed or prevented by chronic electrical stimulation, as would be predicted if neural activity played an essential role in maintaining normal fiber caliber. Chronic stimulation had a small short-term sparing effect in the first month after axotomy but was counterproductive over long periods.
\end{abstract}

Comparison of the time course of the decline in CAP amplitude and reduction of fiber diameters with described alterations in mRNA expression of neurofilament protein indicates that the early atrophy is too rapid to be accounted for by reduced synthesis and transport of neurofilaments. It is more likely to result from modification of axonal proteins after axotomy. Replacement of neural activity with stimulation may reduce the initial atrophy but, over longer periods, exacerbates the atrophy, possibly by affecting the synthesis and transport of cytoskeletal proteins.

These studies show that the trophic control of nerve fiber size is mediated primarily by functional contacts with peripheral targets and that neural activity plays a relatively small role. Without functional contacts, nerve fibers decline in diameter to stable but lower values. The atrophy was exacerbated by imposing neural activity on the relatively quiescent axotomized neurons.

Dramatic changes in physiological and morphological characteristics of axotomized neurons have provided indirect evidence for retrograde trophic control of gene expression and protein synthesis by target cells. Alterations in physiological parameters include reduced action potential amplitude, decreased after-hyperpolarization duration, and slowed nerve conduction velocity

\footnotetext{
Received Aug. 9, 1990; revised Jan. 16, 1991; accepted Feb. 20, 1991.

The support of the Medical Research Council of and Muscular Dystrophy Association of Canada is gratefully acknowledged. We also thank Ms. Susan Buller and Mr. Gary Goldsand for their able assistance in the chronic experiments and Dr. Wolfram Tetzlaff for his helpful comments on the manuscript.

Correspondence should be addressed to Dr. Tessa Gordon, Division of Neuroscience, Heritage Medical Research Center, University of Alberta, Edmonton Alberta, Canada T6G 2S2.

a Present address: Victoria General Hospital, Halifax, Nova Scotia, Canada B3H 2 Y9.

Copyright (C) 1991 Society for Neuroscience $0270-6474 / 91 / 112157-13 \$ 03.00 / 0$
}

(Kuno et al., 1974; Purves, 1975; Davis et al., 1978; Gustafsson and Pinter, 1984; Foehring et al., 1986; Gordon et al., 1987; for reviews, see Gordon, 1983; Titmus and Faber, 1990). Morphological changes in the cell body, the chromatolytic changes, include decentralization of the nucleolus and dissolution of Nissl substance (Nissl, 1892; Liebermann, 1971). Axotomized nerve fiber caliber decreascs (Gutmann and Sanders, 1943; Kreutzberg and Schubert, 1971; Carlson et al., 1979; Risling et al., 1983) concurrent with a decline in conduction velocity (Cragg and Thomas, 1961; Milner et al., 1981; Gillespie and Stein, 1983).

Molecular studies have more recently provided direct evidence for a switch in gene expression after axotomy: levels of messenger RNA and expression of neurotransmitters, rate limiting enzymes for transmitter synthesis and neurofilament (NF) protein decline following axotomy (Grafstein and McQuarrie, 1978; Gordon, 1983; Hoffman et al., 1984; Woolf et al., 1984; Tetzlaffet al., 1988a); other proteins associated with slow axonal transport, actin and tubulin, are upregulated (Hall et al., 1978; Hoffman and Lasek, 1980; Neumann et al., 1983; Sinicropi and McIlwain, 1983; Tetzlaff et al., 1988a), and the axotomized neurons express novel growth-associated proteins (Heacock and Agranoff, 1976; Skene and Willard, 1981; Kalil and Skene, 1986; Tetzlaff et al., 1988a, 1989; Hoffman, 1989; for review, see Skene, 1989). Some of the biochemical changes have been directly correlated with physiological changes. Thus, decline in NF protein may account for the decline in nerve fiber diameter (Hoffman et al., 1983, 1984, 1987; Dyck et al., 1985; Greenberg and Lasek, 1988; Hoffman, 1988) and concomitant increase in latency and decreased amplitude of action potentials on the proximal stump of axotomized nerves (Davis et al., 1978; Gordon and Stein, 1982; Gordon, 1983). Nevertheless, despite the increased understanding of the changes in gene expression after axotomy, the nature of the retrograde trophic regulation of the expression in neurons is still poorly understood.

The trophic influence of target cells on sympathetic and NGFsensitive neurons is likely to be mediated, at least in part, by NGF since exogenous NGF partially reverses retrograde changes in electrophysiological properties in axotomized bullfrog sympathetic neurons (Kelly et al., 1989), decline in NGF rcceptors in a subpopulation of axotomized rat dorsal root ganglion cells, and reduced NF mRNA expression in sensory neurons of the rat facial nucleus (Verge et al., 1990). By analogy, muscles may provide a trophic factor that is taken up by motor nerve terminals for retrograde transport to maintain normal motoneuron properties. The nature of the factor remains uncertain, but it may be the same trophic factor that prevents motoneuronal cell death during embryonic development (Oppenheim and Haverkamp, 1988). It has been suggested that the retrograde supply of trophic material depends on muscle bulk because axotomy- 
Antidromic chronic stimulation
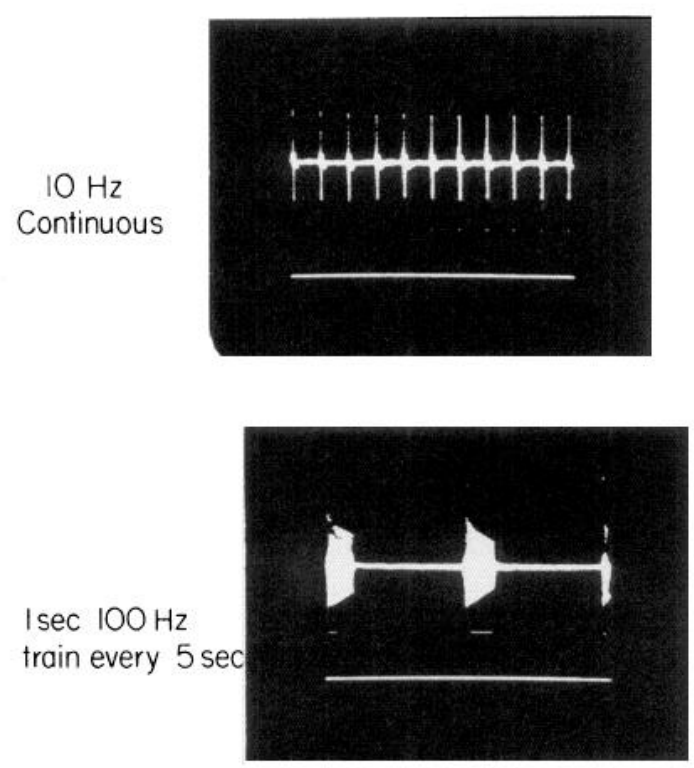

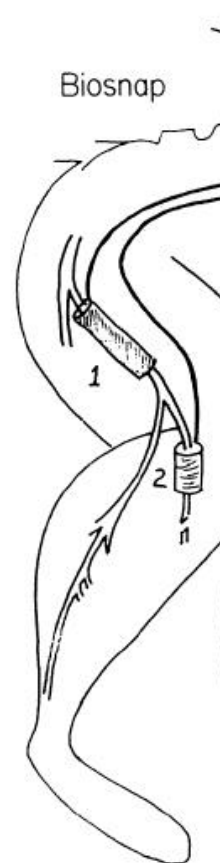

CAP monitoring

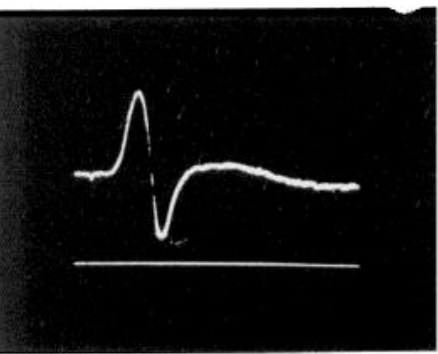

1. Sciatic nerve cuffs

2.Common peroneal nerve cuffs

Figure 1. Schematic diagram of methods for (1) bilateral axotomy and unilateral chronic electrical stimulation of axotomized CP nerves in the rabbit hindlimb with either $10-\mathrm{Hz}$ continuous stimulation or intermittent stimulation at $100 \mathrm{~Hz}$ with a $20 \%$ duty cycle for $8 \mathrm{hr}$ each day and (2) monitoring of triphasic CAPs on the sciatic nerve. Silastic nerve cuffs were led to external devices via a biosnap skin interface (see Materials and Methods, and Davis et al., 1978, for further details).

like changes could be induced in cat motoneurons by various procedures which result in muscle atrophy. These procedures are pharmacological blockade of impulse conduction (Czeh et al., 1978) or neuromuscular transmission (Pinter et al., 1991) and immobilization of muscle in a shortened position (Gallego et al., 1979). Conversely, increase in glandular target size following partial denervation led to an increase in caliber of sympathetic postganglionic axons (Voyvodic, 1989), but the retrograde effects of enlarged targets on myelinated nerves have been found to be small or absent (Edds, 1949; Lutt et al., 1988).

On the other hand, it could be argued that the axotomy-like effects result, at least in part, from the reduced activity of the neuromuscular system rather than reduced muscle bulk and that the hypertrophic effects of increased target size result from increased activity. Young (1950) first suggested that nerves, like muscles, are responsive to their level of activity and may undergo atrophy following disuse. Supporting evidence comes from findings of a small but significant increase in fiber diameter (hypertrophy) of hyperactive nerves (Edds, 1950; Anderson and Edstrom, 1957; Somorajski and Rolsten, 1975; Grainger and Sloper, 1976; Roy et al., 1984) and atrophy of nerves in immobilized limbs (Edds, 1950; Eisen et al., 1973). The finding that sensory nerves atrophied more severely than motor nerves after axotomy (Hoffer et al., 1979; Milner and Stein, 1981) is also consistent with a possible role of neural activity because the more severely affected sensory axons are silenced by isolation from sense organs while the less severely affected motor axons still conduct action potentials in response to activation in the spinal cord (Gordon et al., 1980).

If loss of neural activity is a significant factor in the decline in nerve fiber diameter and associated electrophysiological parameters after axotomy, chronic activation of axotomized nerves should reduce the changes. To determine whether neural activity plays any role in the maintenance of nerve caliber in the PNS, we have, in this study, maintained neural activity by applying chronic electrical stimulation to axotomized nerves. Using implanted extracellular cuff electrodes on the sciatic nerve and one or more of its branches in both hindlimbs of rabbits, we have (1) monitored the compound action potential (CAP) before and after cutting the nerve branch distal to the cuff and (2) imposed high and low frequency stimulation in one but not the other hindlimb. This method has allowed us to use each animal as its own control in determining (1) the extent and time course of atrophy of axotomized nerves by comparing pre- and postoperative measurements of CAP amplitude and latency and (2) the effects of chronic stimulation of the axotomized nerves by comparing stimulated and unstimulated axotomized nerves bilaterally for periods of up to 7 months. We have combined this electrophysiological study with a morphological examination of the nerves at times during the most rapid phase of change in CAP amplitude and latency (see Davis et al., 1978) and at later times when the electrophysiological properties stabilize.

\section{Materials and Methods}

Nerve cuffs containing platinum iridium electrodes (Stein et al., 1975, 1977) were placed around the sciatic nerve and the common peroneal (CP) branch in both hindlimbs in eight adult rabbits $(2.5-4 \mathrm{~kg}$ each and 6-12 months old) under sterile conditions and sodium pentobarbitol anesthesia ( $30 \mathrm{mg} / \mathrm{kg} \mathrm{Nembutal}$ i.p.). In one animal, cuff electrodes were also placed on the tibial (TIB) nerve branch. Cuffs on sciatic and CP nerves were also placed unilaterally in two animals. Leads from the cuff electrodes were led to the skin through a plug held in a biosnap in the skin which was fixed dorsally to the lumbar spinal processes (Fig. 1). Thereby, the leads interfaced with external stimulators and amplifiers for chronic stimulation and recording, respectively. The continuity and stability of the electrodes was monitored by measuring the impedance of the electrodes on a Hewlett-Packard impedance meter (model 4800A).

The amplitude and latency of the CAP were monitored regularly at 
Table 1. Nerve fiber number

\begin{tabular}{|c|c|c|}
\hline Days after axotomy & Unstimulated & Stimulated \\
\hline 0 & $4960 \pm 1548(4)$ & \\
\hline 17 & $5031 \pm 476$ & $5495 \pm 1426(4)$ \\
\hline 38 & $5676 \pm 680$ & $5264 \pm 280$ \\
\hline 87 & $4133 \pm 572$ & $4972 \pm 372$ \\
\hline 227 & $5986 \pm 209$ & $5864 \pm 680$ \\
\hline
\end{tabular}

Mean number $\pm \mathrm{SE}(n)$ of fibers in common peroneal nerves that were axotomized and chronically stimulated and contralateral nerves that were axotomized but not stimulated (see Materials and Methods for further details).

3-10-d intervals before and after axotomy: CAPs were recorded from the sciatic nerve cuff in response to suprathreshold stimulation of the $\mathrm{CP}$ or TIB nerve using square wave pulses of $10-\mu \mathrm{sec}$ duration and $2-$ $8 \mathrm{~V}$ (and in the reverse direction, from sciatic to CP or TIB), with the animals under halothane anesthesia. The threshold and suprathreshold voltages were established daily prior to chronic stimulation and in the recording sessions. Stimulus voltage was increased from $0 \mathrm{~V}$ to just evoke a response (threshold $<1 \mathrm{~V}$ for a $10-\mu \mathrm{sec}$ square wave pulse) and then further increased to evoke the maximal response, namely, when CAP amplitude did not increase further but the stimulus artifact increased proportionately (suprathreshold $=2-8 \mathrm{~V}$ ). Reproducible stable baseline recordings were obtained for 3-4 weeks prior to a second operation in which the rabbits were anesthetized with Nembutal (as above for cuff implantation), and sterile surgical technique was used to cut and ligate either the CP or TIB nerves $2-3 \mathrm{~cm}$ distal to the cuff in both legs. The proximal stump was sutured onto a Silastic sheet to prevent regeneration and reinnervation of denervated targets. The axotomized nerve (CP or TIB) was then stimulated chronically in one leg by suprathreshold square wave pulses of 2.5-8 $\mathrm{V}$ amplitude, 10- $\mu$ scc duration, delivered from a Grass stimulator controlled by a Digitimer (Devices Ltd.). Stimulation was either continuous at $10 \mathrm{~Hz}$ or in trains of 99 pulses at $100 \mathrm{~Hz}$ every $5 \mathrm{sec}$ for $8 \mathrm{hr} / \mathrm{d}$ for periods of up to $230 \mathrm{~d}$.

Evoked CAPs on the sciatic nerves were displayed continuously on an oscilloscope (Textronix 5441) to check stability of the stimulus parameters and to monitor the evoked CAPs. The chosen stimulation parameters, which were generally stable from day to day, evoked maximal CAP amplitude and were below threshold for the pain fibers so that the stimulation did not cause any perceptible distress to the animals. The rabbits were confined in narrow cages that permitted them to stand, to move forward and backward (but not to reverse direction), and to eat and drink freely. There was no perceptible change in the food and water consumption or the sleep patterns of the confined rabbits as compared to rabbits confined to cages in the animal facility. Their weight gain also was similar to that of normal rabbits.

At selected intervals during the rapid decline of CAP amplitude and increase in latency (for cat nerves, see Davis et al., 1978), the experiments were terminated and the nerves prepared for histological examination. Segments of the CP or TIB nerves, proximal to, within, and distal to the nerve cuff, were fixed in gluteraldehyde $(3 \%$ in $0.1 \mathrm{M}$ phosphate buffer), stained with $\mathrm{OsO}_{4}(3 \%$ solution in $0.1 \mathrm{M}$ phosphate buffer), dehydrated in ascending alcohols, and embedded in araldite. One-micron cross sections were mounted, stained ( $1 \% p$-phenylenediamine), and microphotographed for measurement (see Gillespie and Stein, 1983). The possible artifacts of nerve cuff placement were controlled for by taking fiber size and number measurements from nerve samples proximal, within, and distal to the cuff. The nerves distal to the cuff were examined at least $1 \mathrm{~cm}$ proximal to the cut end of the nerve where there was no evidence of demyelination and remyelination such as has been reported to occur several internodes proximal to axonal injury (Lubinska, 1961; Spencer and Thomas, 1970; Dyck et al., 1981). Fiber size and number were not affected by placement of the cuff since the values did not differ significantly in the samples taken at different locations relative to the cuff location. For example, the mean fiber diameter \pm SE of an axotomized CP nerve was $5.26 \pm 0.22,5.22 \pm 0.17$, and 4.86 $\pm 0.18 \mu \mathrm{m}$ for 74,83 , and 70 fibers measured in cross sections taken proximal; within, and distal to the CP recording cuff, respectively. Thus, we are reasonably confident that the placement of the nerve cuff did not introduce significant errors in fiber diameter and number measure-

\section{Table 2. Bilateral nerve cuffs and preoperative measurements of} CAP

\begin{tabular}{lcc} 
Nerve cuffs & Left hindlimb & Right hindlimb \\
\hline CP cuff length $\times$ diameter $(\mathrm{mm})$ & $22 \times 1.57$ & $22 \times 1.57$ \\
CP cuff impedance $(\mathrm{k} \Omega)$ & $1.82 \pm 0.21$ & $2.11 \pm 0.32$ \\
CP CAP amplitude $(\mu \mathrm{V})$ & $575 \pm 102$ & $678 \pm 151$ \\
CP CAP latency $(\mu \mathrm{sec})$ & $456 \pm 37$ & $520 \pm 51$ \\
Sciatic cuff length $\times$ diameter $(\mathrm{mm})$ & $30 \times 3.35$ & $30 \times 3.35$ \\
Sciatic cuff impedance $(\mathrm{k} \Omega)$ & $1.81 \pm 0.27$ & $1.69 \pm 0.27$ \\
Sciatic CAP amplitude $(\mu \mathrm{V})$ & $1073 \pm 162$ & $\mathbf{8 6 1} \pm 176$ \\
Sciatic CAP latency $(\mu \mathrm{sec})$ & $505 \pm 53$ & $478 \pm \mathbf{4 4}$
\end{tabular}

Mean ( \pm SE) of nerve cuff impedance values and amplitude and latencies of CAPs evoked on the CP and sciatic nerves in left and right hindlimbs of eight cats in response to supramaximal anterograde and retrograde stimulation, respectively. (For further details, see Results.)

ments. All graphs show data that was obtained at the same level of the ncrve, which was $1-2 \mathrm{~cm}$ from the cut end of the nerve.

Sample areas were photographed and printed at magnification of 1200 $2000 \times$ for digitization of the outer perimeter of the myelinated axons. Total fiber numbers in the CP nerve were calculated by counting fibers in four to eight sample photographs of the nerve cross section at the same magnification and by multiplying the average count by the ratio of the area of the whole nerve to the area of the sample counted (Table 1; see also Gutmann and Sanders, 1943). Samples of between $700(15 \%$ of the total) and $5094(100 \%$ of the total) nerve fibers were examined from randomly selected areas of the nerve cross section for representation of the fiber size distribution. There are normally three to five fascicles that contain different populations of nerve fibers with respect to size. Generally, $56 \%$ of the cross-sectional area of the whole nerve contained most of the larger nerve fibers and the other $44 \%$ contained most of the smaller nerve fibers; the latter represents the larger proportion of the nerve fibers (see Fig. 6). We weighted the average counts of the large fibers by the ratio of the two areas (1.27) to adjust for this heterogeneity.

A Summa graphics (MM1200 series) digitizing tablet coupled to a Kaypro 2000 PC computer was used for digitization, and a program written locally by Mr. Robert Rolf used the outer perimeter to determine the fiber area and, in turn, the diameter of an equivalent circle. Electronmicroscopic photomicrographs were used to digitize the outer perimeter and the axon perimeter (inside the myelin sheath) of fibers to determine the myelin thickness from the difference between fiber and axon diameters, as described by Gillespie and Stein (1983).

Statistics. Differences between means was calculated using the Student's $t$ test, and differences were regarded as significant if the probability was less than $1 \%$. Differences between distributions were analyzed using the Kolmogorov-Smirnov test to compare cumulative distributions as described in detail by Fisz (1963). Briefly, the maximum vertical separation between points on cumulative frequency histograms $(D)$ is measured to calculate $\lambda$, where $\lambda=D n^{0.5}$ and $n$ is the total number of sampled fibers (in the case of distributions of fiber diameters). If $\lambda<$ 1.36 , differences in the fiber diameter distributions are not significant at the $5 \%$ level. If $\lambda>1.63$ or 1.94 , the distributions are significantly different at the 1 and $0.1 \%$ levels of confidence, respectively. Frequency distributions were also compared using the Mann-Whitney $U$ test with the same result.

\section{Results}

\section{Compound action potentials}

Retrograde CAPs were elicited by maximal stimulation of the CP or TIB nerves and recorded from cuffelectrodes on the sciatic nerve. Conversely, anterograde CAPs were recorded from cuff electrodes placed on the CP and TIB nerves in response to stimulation of the sciatic nerve. On average, the mean amplitude and latency of CAPs recorded prior to axotomy were similar bilaterally (Table 2). CAP amplitude was higher on the sciatic nerve cuffs because amplitude depends not only on size of the nerve fibers but also on the dimensions of the cuff electrode, which in the case of the sciatic nerve cuff was longer than the 


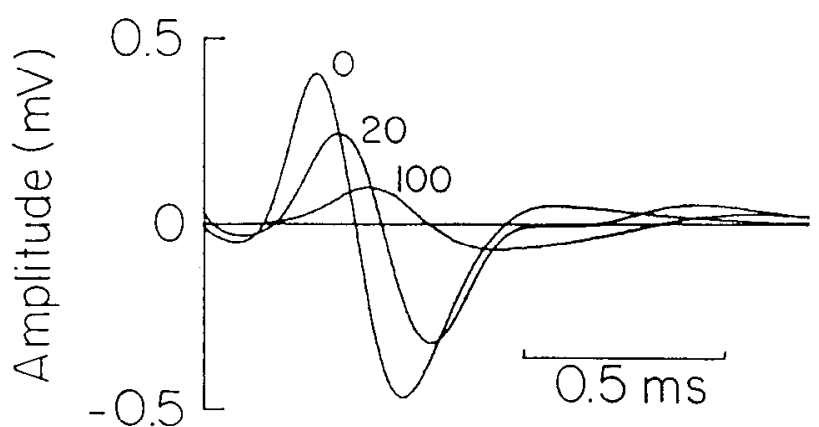

Figure 2. Triphasic compound action potentials recorded on a nerve cuff electrode on the C.P nerve in response to supramaximal stimulation of the sciatic nerve, 0,20 , and $100 \mathrm{~d}$ after cutting and ligating the $\mathrm{CP}$ nerve, $25 \mathrm{~mm}$ distal to the cuff.

CP cuff (Stein et al., 1977; Davis et al., 1978). After section and ligation of the CP or TIB nerves $2-3 \mathrm{~cm}$ distal to the cuff, CAP amplitude declined and latency to the first peak increased as shown in the example in Figure 2. Potentials recorded on the sciatic and the nerve branch electrodes showed the same relative changes in peak-to-peak amplitude and latency: a rapid decline or increase, respectively, to a plateau level at times longer than $100 \mathrm{~d}$ (Fig. 3).

One of the two hindlimbs was chosen at random for stimulation with either the $10-\mathrm{Hz}$ continuous or $100-\mathrm{Hz}$ intermittent pattern of stimulation, which was commenced on the day of axotomy. During chronic stimulation, CAPs were evoked only on the stimulated side and were not detected on the contralateral side. The amplitude and the latency of CAPs declined whether or not the nerves were chronically stimulated. This is clear from Figure 4 where the mean $( \pm$ SE) of the amplitude and latency of CAPs are plotted relative to preoperative values. There was no detectable difference in the extent or time course of decay of the CAP in stimulated and unstimulated axotomized nerves. Three of the experimental nerves were treated with $100-\mathrm{Hz}$ intermittent stimulation, and the other four were stimulated for the same daily $8-\mathrm{hr}$ period with continuous $10-\mathrm{Hz}$ stimulation. Thus, irrespective of frequency, the stimulation appeared to be ineffective in reducing the decay of the CAP amplitude or the increase in the latency after axotomy. The same result was obtained in the one animal in which the TIB nerve was ligated and stimulated. Again, the CAP amplitude fell to $20 \%$ of its preoperative levels, and there was no perceptible difference between the stimulated and unstimulated TIB nerves. To check for bilateral crossover effects of stimulation, nerves were axotomized unilaterally in two animals. Similar results were obtained for stimulated and nonstimulated axotomized nerves.

The decline in CAP amplitude could be fitted with a simple exponential with the decline being most rapid in the first month of axotomy, although there is some evidence of two exponential time courses. Values of amplitude and latency tended to level off for a short period of time at around 1 month before continuing to decline or increase, respectively, in a second exponential to the final plateau level (Fig. 4). When single exponentials were fitted to the data for each animal, the amplitude fell to an average $( \pm \mathrm{SE})$ asymptotic value of $15.6 \pm 3 \%$ of preoperative levels in the stimulated nerves and $13.9 \pm 4 \%$ in the unstimulated axotomized nerves, with time constants $(\tau)$ of $45+4$ and $41+$ $4 \mathrm{~d}$, respectively. These results are in good agreement with previous data for axotomized hindlimb nerves in the cat (Davis et al., 1978).
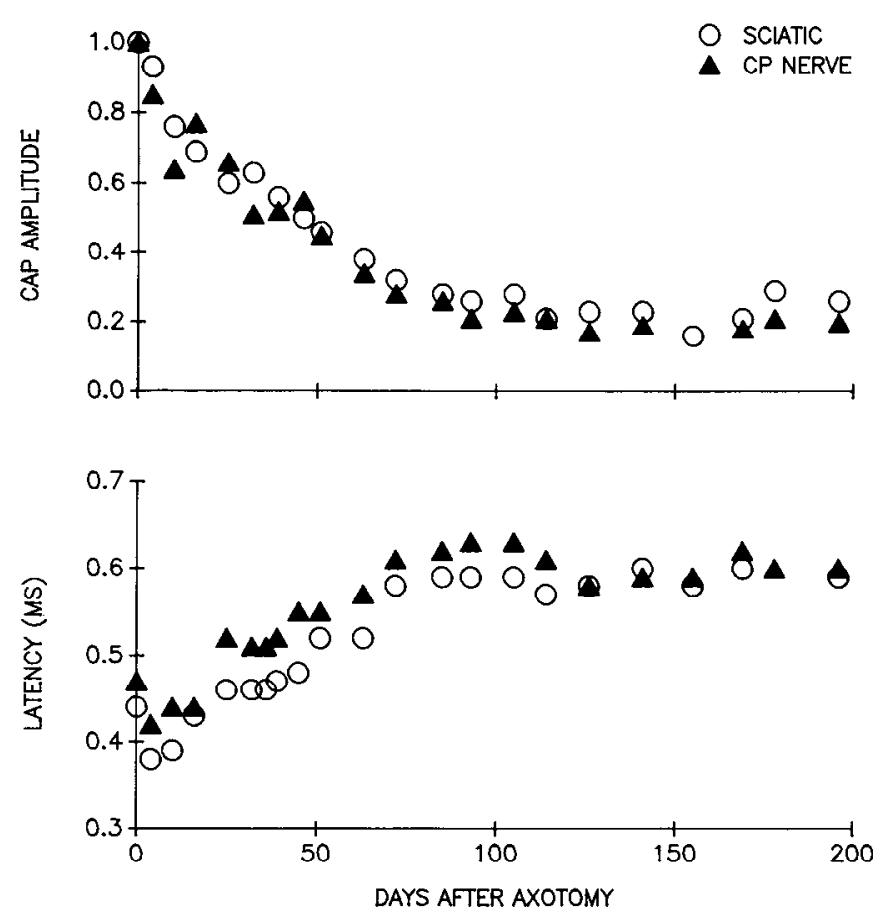

Figure 3. Changes in amplitude, normalized to preaxotomy values, and latency of CAPs recorded at regular intervals after axotomy, on the sciatic (open circles) and CP nerve cuffs (filled triangles) in response to stimulation of the CP and sciatic nerves, respectively.

In one animal, the CAP was monitored bilaterally for a period of $227 \mathrm{~d}$ as shown in Figure 5. The amplitudes of the CAPs recorded in both nerves level off toward a plateau, but the stimulated nerve CAP continues to decline slightly more than the unstimulated nerve CAP, which remains stcady. There was no detectable difference in the latency to the first positive peak for the two nerves.

\section{Nerve fiber diameter}

The diameter of myelinated fibers in normal CP nerves from a control animal range from 1 to $160-\mu \mathrm{m}$. The distribution is bimodal, with a large peak around 3 and a small peak at $12 \mu \mathrm{m}$ diameter (Fig. 6). Stimulated and unstimulated axotomized nerves were removed for morphometric analysis (see Materials and Methods) at times which corresponded with $0.5,1,2$, and 5 times the time constant $\tau$ for the exponential decline in the CAP amplitude. The distributions of fiber diameters of stimulated and unstimulated contralateral nerves are compared in Figure 7 during the rapid phase of decline in CAP amplitude at 17, 38, and $87 \mathrm{~d}$ after axotomy (Fig. 7). As first described by Gutmann and Sanders (1943), the bimodal distributions bccome unimodal as the numbers of large fibers decline (Figure 7). The extent of atrophy and the progression with time are readily apparent when the distributions are plotted as cumulative frequency histograms and compared to the normal fiber distribution plotted as circles in Figure $7 B$. Comparisons of the cumulative frequency distributions showed that all axotomized nerve fibers are already significantly smaller than nurmal by 17 $\mathrm{d}$ at the $0.1 \%$ level of confidence $(\lambda>1.94$, Kolmogorov-Smirnov test, see Materials and Methods) and that the stimulated axotomized nerves had not atrophied as much as the unstimulated axotomized nerves $(p<0.01)$. This small but significant effect of stimulation on atrophy of axotomized nerves was not 

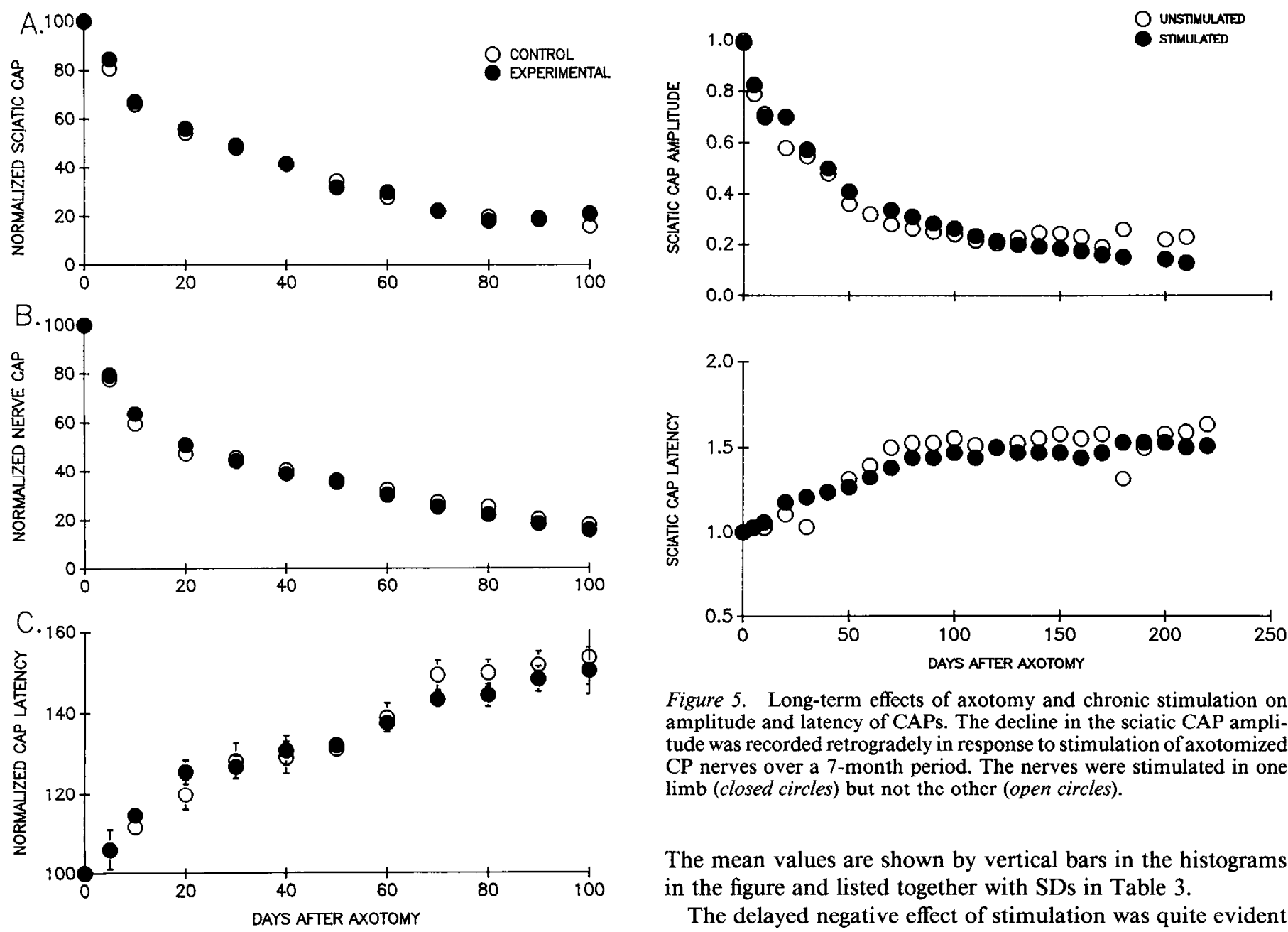

Figure 5. Long-term effects of axotomy and chronic stimulation on amplitude and latency of CAPs. The decline in the sciatic CAP amplitude was recorded retrogradely in response to stimulation of axotomized $\mathrm{CP}$ nerves over a 7-month period. The nerves were stimulated in one limb (closed circles) but not the other (open circles).

The mean values are shown by vertical bars in the histograms in the figure and listed together with SDs in Table 3.

The delayed negative effect of stimulation was quite evident $100 \mathrm{~d}$ or more after axotomy when there was a significant shift

Figure 4. Changes in the mean $( \pm \mathrm{SE})$ values of amplitude of CAPs on $(A)$ the sciatic nerve, $(B)$ the $C P$ nerve, and $(C)$ latencies from control axotomized and unstimulated nerves (open circles) and contralateral axotomized and stimulated nerves (closed circles) in seven rabbits. SE bars are obscured by the symbols except for the latencies. Values were normalized to preoperative values $(100 \%)$ and then averaged. The nerves were axotomized $20-30 \mathrm{~mm}$ distal from the CP nerve cuff.

scen a month later when the percentage increase of small fibers in axotomized nerve was the same whether or not the nerves were stimulated. By $90 \mathrm{~d}$, the trend was reversed and the fiber distribution included significantly more smaller fibers in the stimulated nerves than the unstimulated nerves $(p<0.01)$. These trends may also be seen when mean values are compared.

\begin{tabular}{lll}
\hline Table 3. Nerve fiber diameter & \\
& & \\
Days after axotomy & Unstimulated & Stimulated \\
\hline 0 & $6.55 \pm 3.82(453)$ & \\
17 & $5.32 \pm 2.14(719)$ & $5.86 \pm 2.87(973)$ \\
38 & $4.74 \pm 2.72(584)$ & $5.02 \pm 2.67(675)$ \\
87 & $5.23 \pm 1.69(736)$ & $3.82 \pm 1.94(2728)$ \\
105 & $4.75 \pm 1.55(1170)$ & $2.89 \pm 1.14(983)$ \\
227 & $4.42 \pm 2.07(2223)$ & $2.78 \pm 1.14(5094)$
\end{tabular}

Mean diameter \pm SD $(n)$ of fibers in common peroneal nerves that were axotomized and chronically stimulated and contralateral nerves that were axotomized but not stimulated. Mean values for unstimulated and stimulated are significantly different $(p<0.1)$ for all time periods except at $38 \mathrm{~d}$. of the distribution to smaller values $(p<0.01$, Fig. 8$)$ and when the CAP amplitude appeared to decline more in the stimulated than the unstimulated axotomized nerves (Fig. 5). Note that there were still fibers as large as $13 \mu \mathrm{m}$ in the axotomized nerves, which, although few in number, could account for the finding that the CAP latency plateaued $100 \mathrm{~d}$ after axotomy, whether or not the nerves were stimulated (Fig. 3). The increase in the proportion of small fibers in the long-term axotomized nerves was not attributed to alterations in numbers of axons, either a decrease due to cell death or an increase due to axonal sprouting proximal to the ligature, because the number of fibers in the

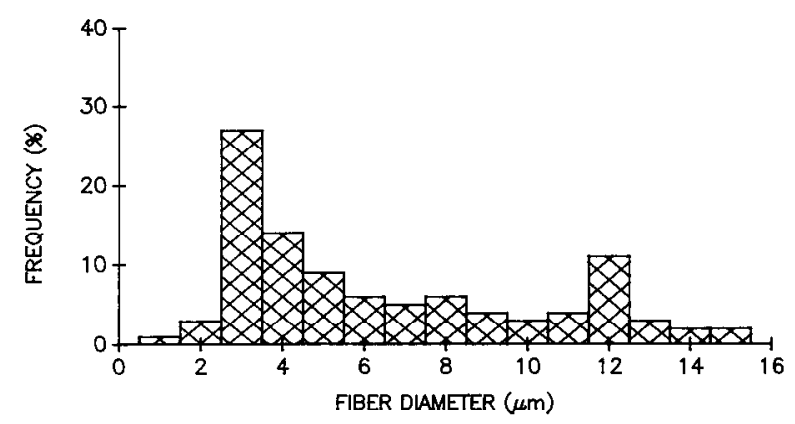

Figure 6. Bimodal frequency distribution of fiber diameters in the common peroneal nerve of a normal rabbit. The mean $\pm S E$ of the fiber diameters is $6.55 \pm 3.82 \mu \mathrm{m}(n=2348)$. 

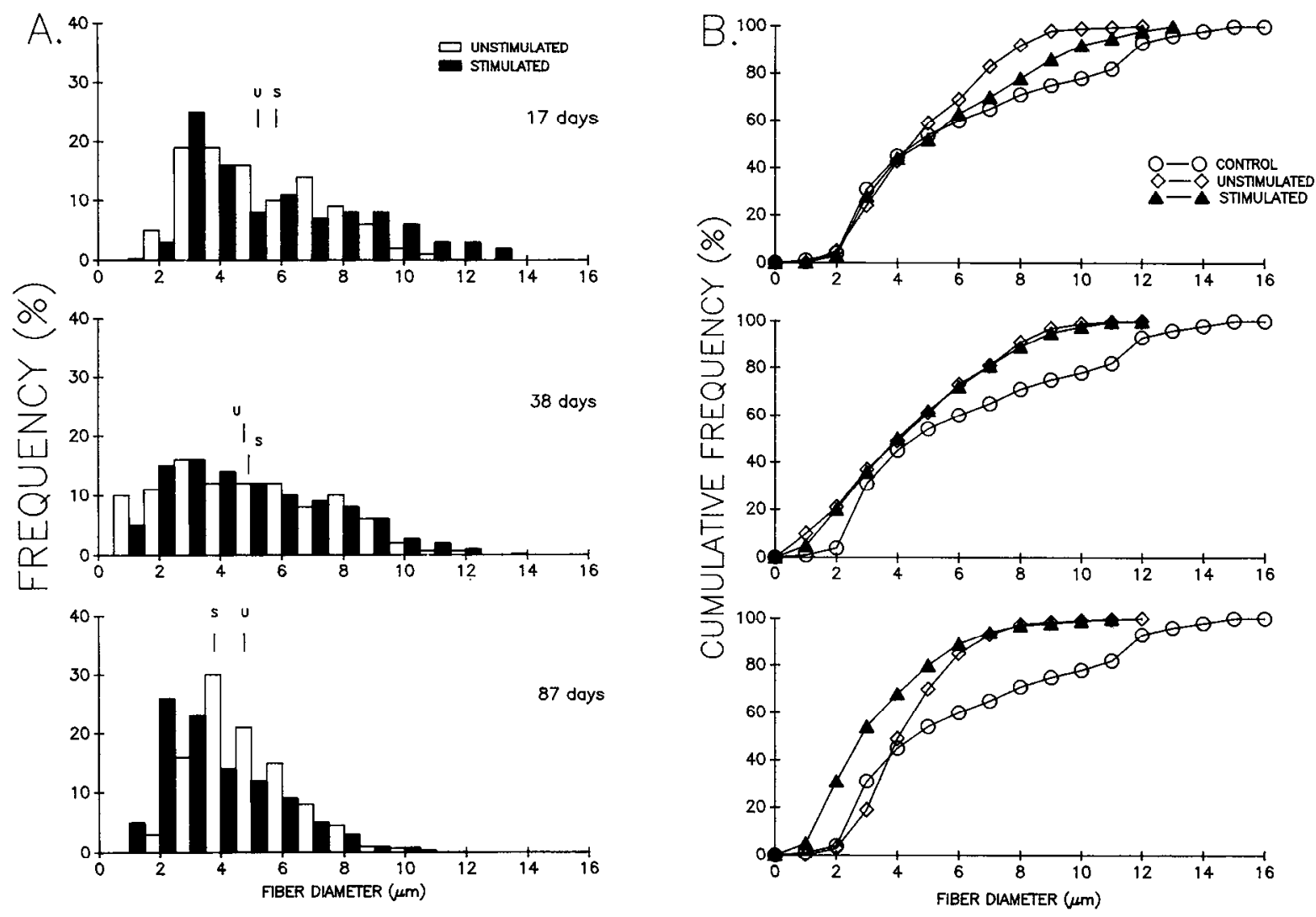

Figure 7. A, Bilateral comparisons of frequency distributions of fiber diameters in axotomized CP nerves, $15 \mathrm{~mm}$ proximal to the site of axotomy, at three time points during the rapid decline in amplitude of the recorded CAP. The nerves that were stimulated $(S)$ are shown as filled bars to contrast with the unstimulated nerves $(U)$ in the unfilled bars. The histograms in panel $A$ are redrawn as cumulative frequency histograms in panel $B$ to compare with the fiber distribution from a normal nerve (open diamonds). The vertical lines denote the mean fiber diameters of the stimulated axotomized CP nerve $(S)$ and the contralateral unstimulated axotomized nerve $(U)$. Differences between distributions were determined using the Kolmogorov-Smirnov test and between means by the Student's $t$ test. At all time periods, the fiber distributions and means of the axotomized nerves were significantly different from normal $(p<0.01)$. Except at $38 \mathrm{~d}$ the stimulated and nonstimulated axotomized nerves were significantly different at the $1 \%$ level of confidence. Mean \pm SD values of fiber diameters are listed in Table 3.

stimulated axotomized and nonstimulated nerves was similar (Table 1).

Examination of axotomized CP nerves at the light and electron microscopic levels showed that, despite the atrophy, the fibers are healthy in appearance and they remain well myelinated (Fig. 9), even the smallest fibers (Fig. 10). Note that the nonmyelinated nerves that are present in the $\mathrm{CP}$ are also present in the axotomized nerves. The myelin thickness of normal and axotomized nerves was measured from electron micrographs and plotted as a function of the fiber diameter as shown in Figure 11. The strong correlation between myelin thickness $(m)$ and equivalent fiber diameter $(D)$ in normal nerves remained in axotomized nerves, despite the decline in fiber diameter. The slope of the regression lines fitted to the data for the axotomized nerves varied between 0.85 and 1.32 and did not differ significantly from normal. Moreover, there was no difference between stimulated and unstimulated axotomized nerves. Since the slope of the regression line does not change, it follows that the axonal diameter declines in proportion to the fiber diameter.

\section{Discussion}

The major findings in this study are that the decline in nerve fiber diameter is rapid after axotomy and that it is not reversed or prevented by chronic electrical stimulation as would be predicted if neural activity played an essential role in maintaining normal fiber caliber. Although there was a short-term sparing effect of the stimulation in the first 3 weeks after axotomy, the maintained stimulation was counterproductive over long periods and exacerbated the atrophy of the axotomized nerves.

\section{Rapid fiber atrophy after axotomy}

With chronic recording techniques that permit the measurement of CAPs on the same nerve before and after axotomy, we have shown that nerve fiber atrophy occurs very rapidly after axotomy: CAP amplitude declined sharply during the first 3 weeks (Figs. 4, 5). Concurrently, there was a dramatic reduction in fiber diameters of the nerves examined at the same level of recording, namely, $\sim 2-3 \mathrm{~cm}$ proximal to the site of axotomy (Figs. 7, 8). These results confirm and extend our earlier electrophysiological studies of axotomized cat nerves (Davis et al., 1978) and show further that the shift from a normal bimodal to a unimodal distribution of fiber diameters (Gutmann and Sanders, 1943; Aitken and Thomas, 1962; Carlson et al., 1979; Dyck et al., 1981; Gillespie and Stein, 1983; Risling et al., 1983) occurs very rapidly after axotomy. They also show that the rapid decrease in CAP amplitude and increase in latency is concomitant with the loss of the larger peak of the bimodal distribution of nerve fibers.

Although the decline in CAP amplitude could be fitted with a single exponential with an average time constant of $\sim 45 \mathrm{~d}$ as 

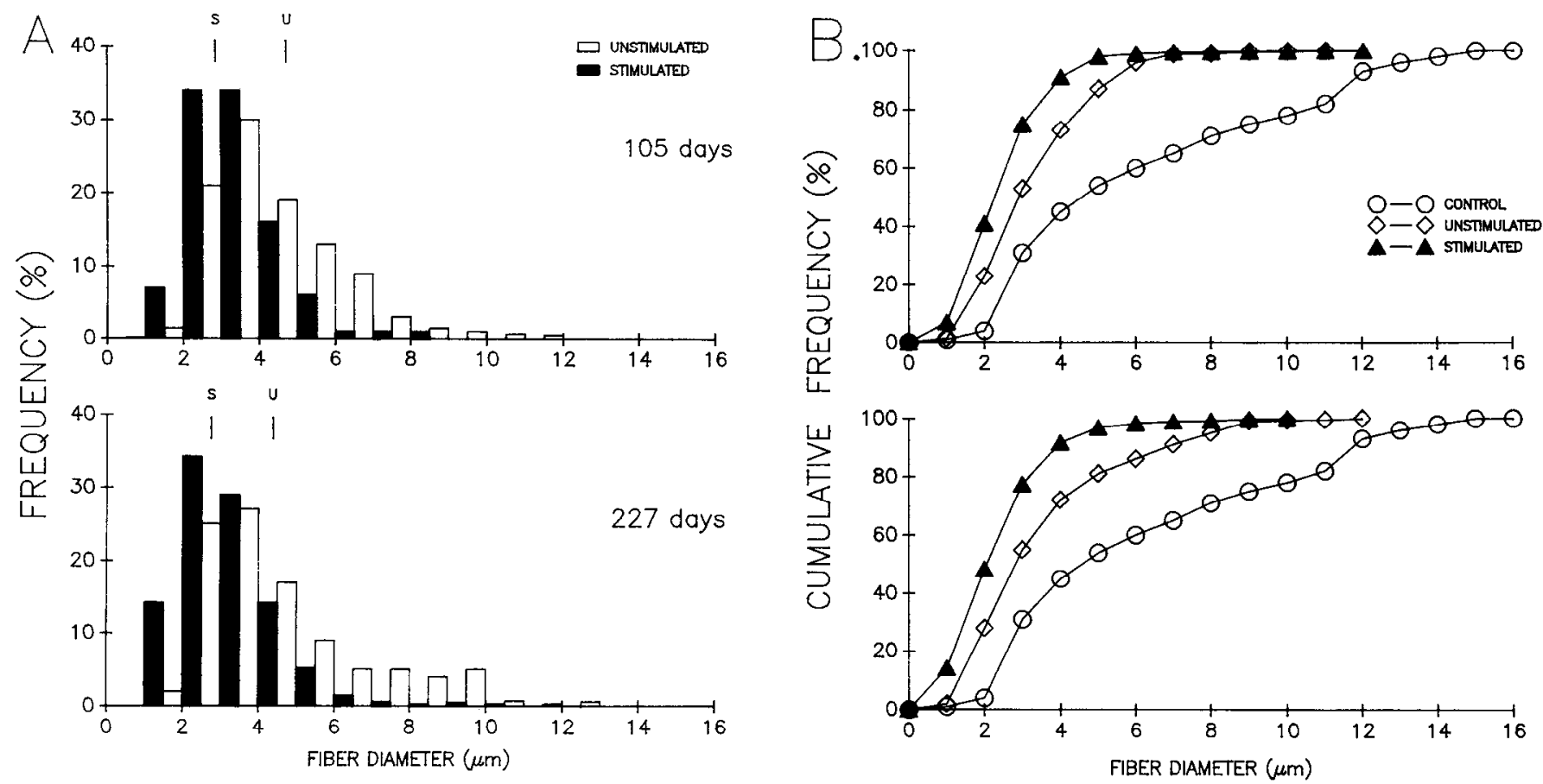

Figure 8. Comparison of frequency histograms $(A)$ and cumulative distributions $(B)$ of fiber diameters of stimulated axotomized and unstimulated axotomized CP nerves at time points when the CAP amplitude has stabilized at a lower but stable level (see Fig. 5). The stimulated axotomized nerves (filled bars and triangles) were significantly smaller than nonstimulated axotomized nerves (open bars and diamonds) at the $1 \%$ level of confidence. Mean \pm SE values of fiber diameters are shown in Table 3 and as vertical lines in $A$.

described previously for axotomized cat hindlimb nerves (Davis et al., 1978), two separate stages of decline of CAP and increase in latency were discernible. The rapid rate of decline in CAP amplitude and increase in CAP latency during the first $20 \mathrm{~d}$ after axotomy was followed by a slower rate of change during the next $80 \mathrm{~d}$. These two phases are paralleled by a leftward shift of the cumulative fiber diameter histograms, a large shift at $17 \mathrm{~d}$ being followed by a relatively smaller change in the next $80 \mathrm{~d}$ (Fig. 12A).

Since fiber numbers do not decline after axotomy of adult nerves (Table 1; Carlson et al., 1979; Gillespie and Stein,1983; but see Dyck et al., 1985) and other factors that may influence the CAP, including internodal distance and myelination, are not altered after axotomy (Cragg and Thomas, 1961; Fig. 11), the changes in the CAP were attributed to decline in fiber diameters. A significant loss of sensory fibers was found after axotomy of immature neurons (Aldskogius and Risling, 1981) and after limb amputation in the adult cat (Dyck et al., 1985). In the latter case, the more severe injury of limb amputation severed nerves closer to the cell bodies than in our study. We cannot discount that there was a small but undetected loss of sensory fibers, which could contribute to the decline in CAP amplitude in our study, even though the axotomy was a less severe injury and was performed close to the endorgans and not close to the cell bodies. In addition, we cannot discount that small fibers were included in our measurements as a result of regeneration of sprouts from the cut and sutured end of the nerve. Sprouts may grow retrogradely along the proximal nerve stump because they are frustrated from growing distally by the suture of the ligated end of the nerve to a Silastic sheet (see Materials and Methods), but they are unlikely to have become myelinated and therefore to have been included in our measurements.
There is good evidence that nerve fiber caliber is correlated with the axonal content of NF protein, with a decrease in caliber occurring with a decline in NF protein after axotomy (Friede and Samorajski, 1970; Hoffman et al., 1987). Alterations in gene expression for NF are seen very soon after axotomy (within 12 $\mathrm{hr}$ ), and a reduction in protein synthesis in the cell body is already evident a day after axotomy (Hoffman et al., 1987; Wong and Oblinger, 1987; Greenberg and Lasek, 1988; Tetzlaff et al., 1988a,b, 1989). However, since neurofilaments are transported to the axons via the slow component SCa of axonal transport (Hoffman and Lasek, 1975), a delay would be expected before axonal NF content fell and, if NF fiber content is a major determinant of fiber caliber (Hoffman et al., 1987), there should be a delay before fiber atrophy. This delay would equal the time taken for lowered amounts of synthesized neurofilaments to be transported. For the rabbit CP nerves that we examined at a distance of $13-15 \mathrm{~cm}$ from the cell body, a delay in nerve atrophy of 50-60 d would be predicted because the rate of advance of moving front of neurofilaments is $\sim 2.5 \mathrm{~mm} / \mathrm{d}$ (Tetzlaff and Bisby, 1989). However, our chronic experiments show that the CAP had already decreased by more than $66 \%$, and the large fiber population had atrophied by $\sim 50 \%$ at $50-60 \mathrm{~d}$, when the initiation of decline was predicted. Furthermore, the reduction in CAP amplitude relative to preoperative values was the same whether CAPs were recorded at the level of the sciatic nerve or the CP or TIB nerve branch and not different (Figs. 3,4) as would be predicted by the proximodistal transport of neurofilaments and the observation of a proximodistal gradient of nerve fiber atrophy after axotomy (Hoffman et al., 1983).

The discrepancies between rapid fiber atrophy and rate of transport of lowered numbers of neurofilaments suggest that local changes in the axotomized nerves rather than alterations 

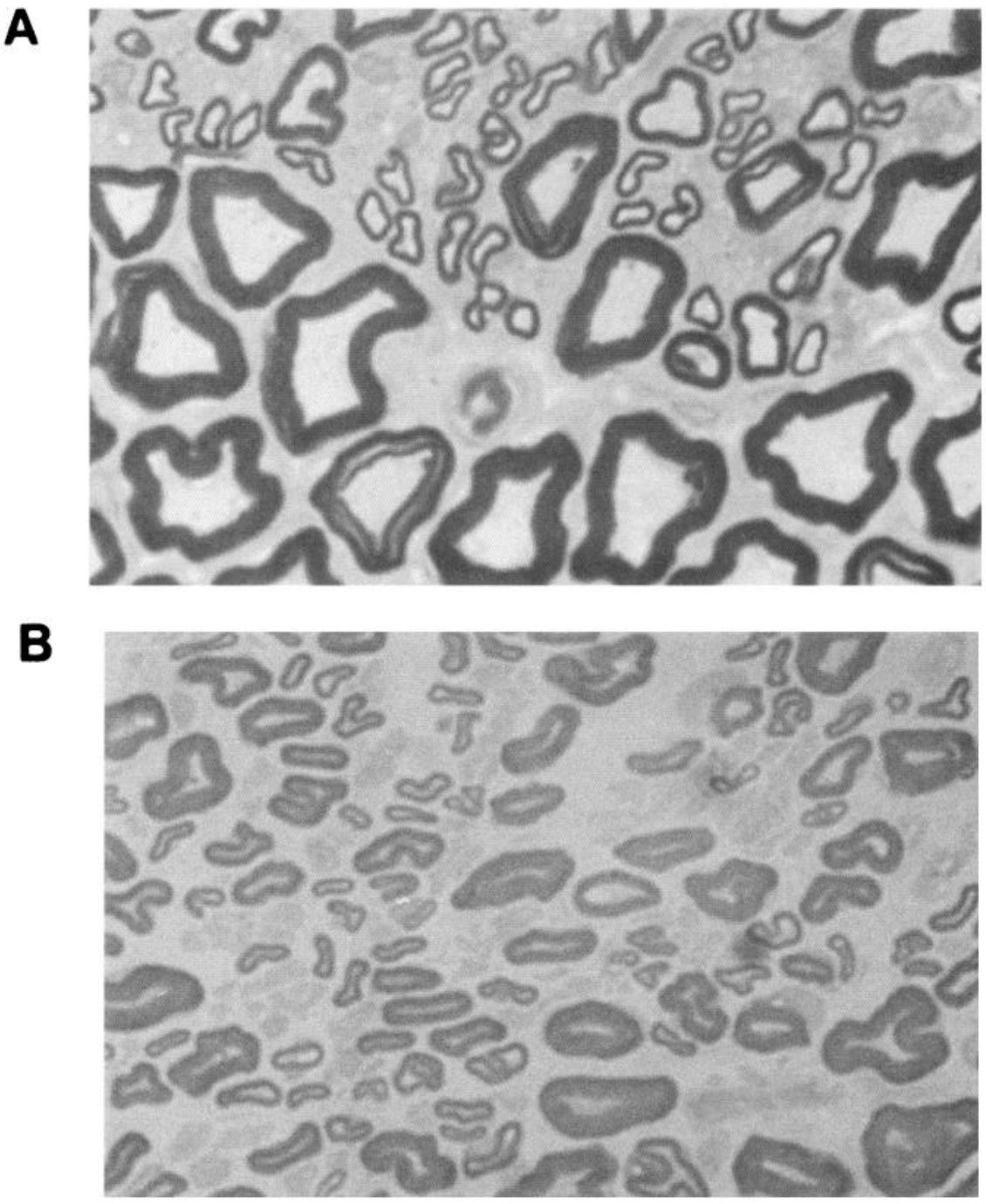

Figure 9. Comparisons of cross sections of normal $(A)$ and axotomized $\mathrm{CP}$ nerves $(B, C)$. CP nerves were sectioned and ligated bilaterally at a distance of $25 \mathrm{~mm}$ from the cuff electrode. The left $\mathrm{CP}$ nerve $(C)$ was chronically stimulated in trains at 99 pulses at $100 \mathrm{~Hz}$ every $5 \mathrm{sec}$ for $8 \mathrm{hr} / \mathrm{d}$ for $227 \mathrm{~d}$, and the right $\mathrm{CP}$ was not stimulated, except during recording sessions $(B$; see Fig. 5$)$. The cross sections were obtained $15 \mathrm{~mm}$ from the site of ligation. Note the greater proportion of large fibers in the normal nerve $(A)$ relative to axotomized nerves and the larger proportion of large fibers in the unstimulated $(B)$ as compared to the stimulated $(C)$ axotomized nerves. Magnification, $984 \times$.

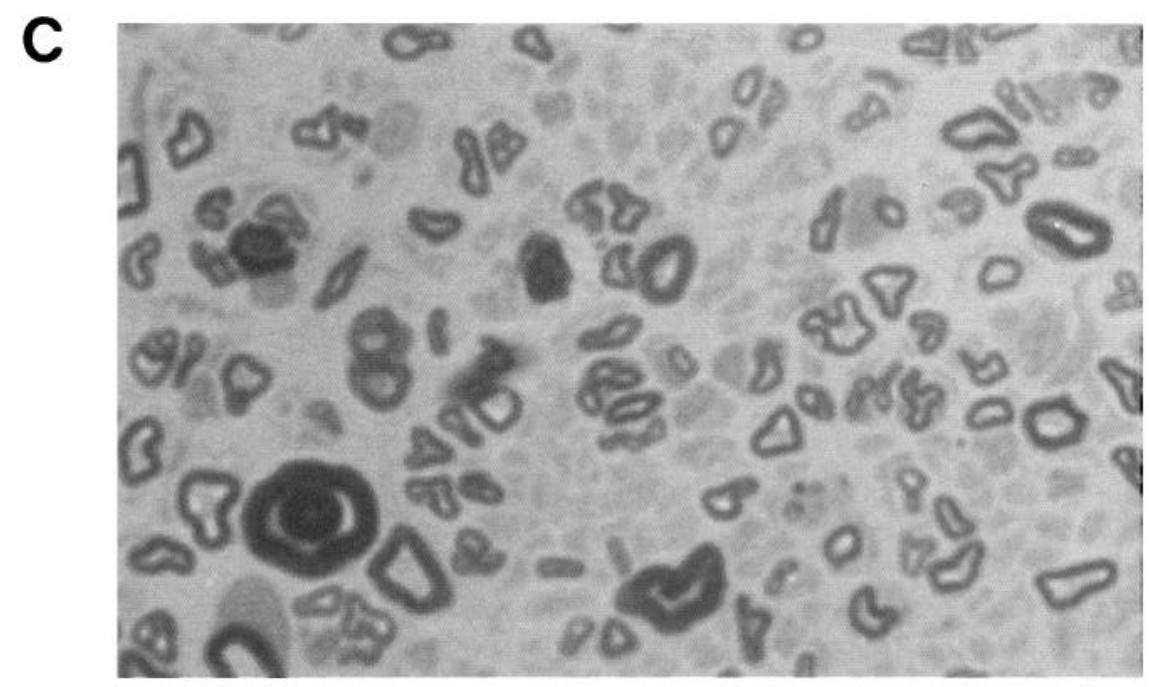

in cytoskeletal protein synthesis and transport are more likely to account for the first rapid phase of decline in fiber caliber after axotomy. Polymerization of neurofilaments is sensitive to several local factors that may operate to reduce their number. These include changes in local concentrations of calcium, so- dium, and hydrogen, which may be involved in alterations in cytoskeletal proteins. In addition, substances may be taken up at the injury site and contribute to local changes during the first phase of decline as well as to later changes in gene expression after retrograde transport to the soma. Our results suggest that 
A

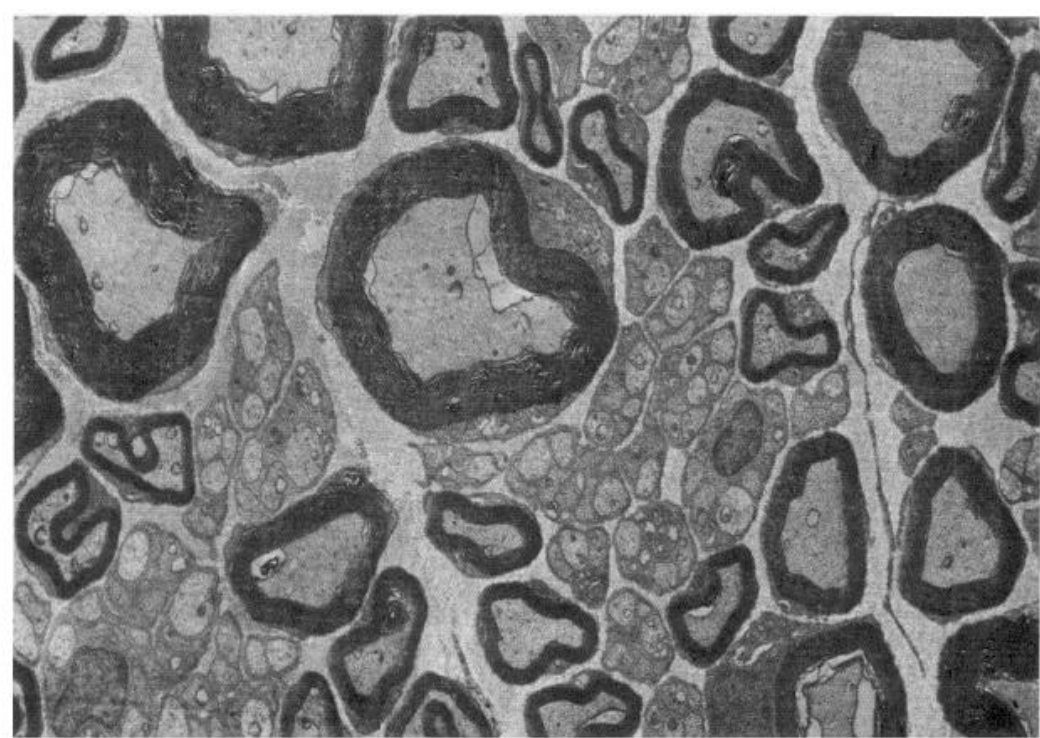

B

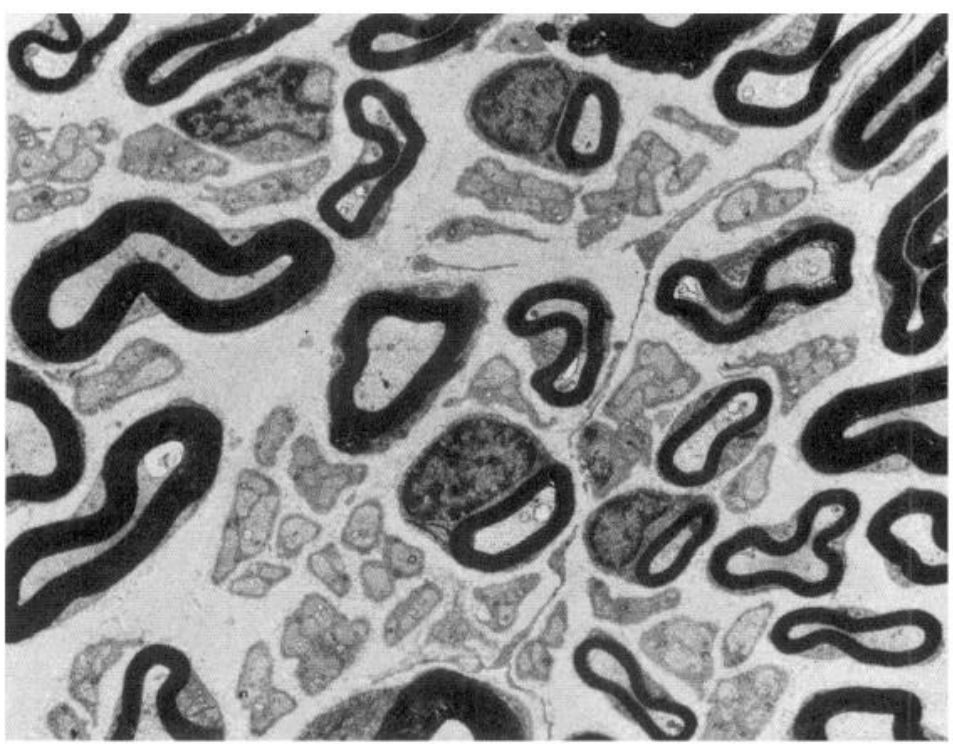

C

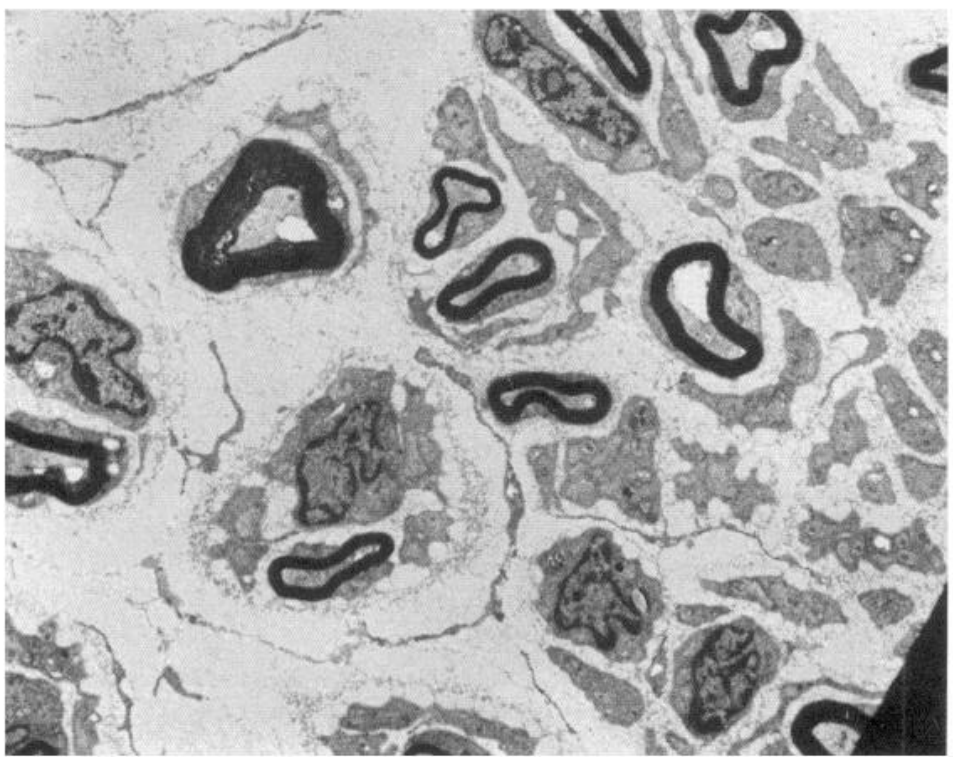

Figure 10. Electron micrographs of cross sections taken from normal $(A)$, unstimulated $(B)$, and stimulated $(C)$ $\mathrm{CP}$ nerves, $227 \mathrm{~d}$ after axotomy and nerve ligation. Magnification, 5270x. 


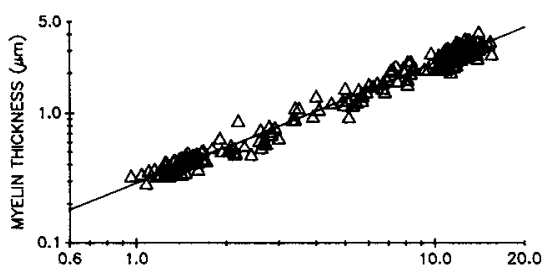

Figure 11. Relationship between myelin thickness and fiber diameter in normal and in $(A)$ stimulated axotomized and $(B)$ unstimulated axotomized $C P$ nerves. Note that the slope of the regression line on the double logarithmic plots does not change in the axotomized nerves whether they are stimulated or not. The slopes of the regression lines are 0.92 for the normal nerve (regression coefficient of 0.99$),(A) 0.99,1.01$, and 1.32 for 17,87 , and $227 \mathrm{~d}$ after axotomy without stimulation (regression coefficients of $0.99,0.94$, and 0.85 ) and $(B) 1.02,1.13$, and 1.08 for 17,87 , and $227 \mathrm{~d}$ after axotomy and chronic stimulation (regression coefficients of $0.88,0.80$, and 0.89 ).
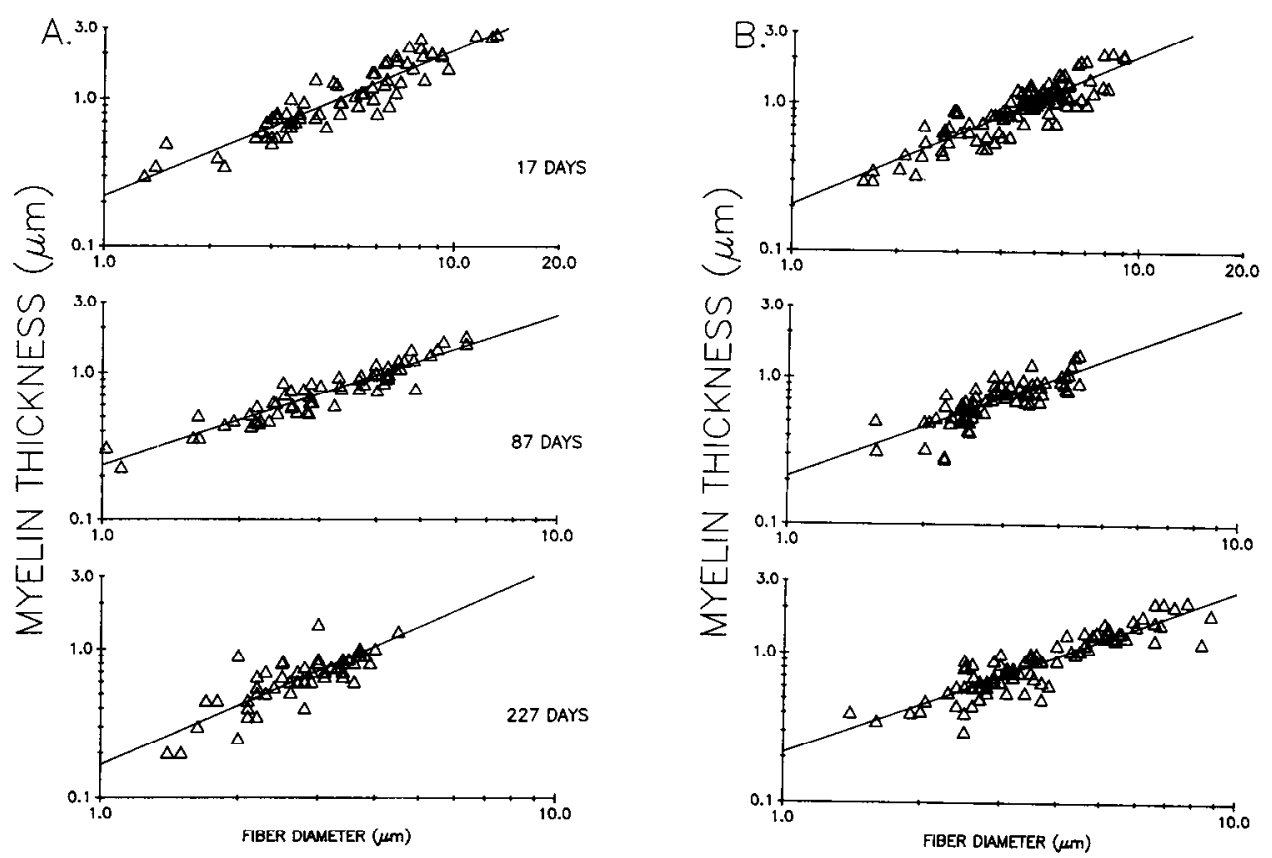

altered expression of cytoskeletal proteins and transport of a reduced number of neurofilaments in the axotomized nerves are more likely to contribute more to the slower phase of atrophy and to the final stabilization of fiber diameters at their lower asymptotic levels. Levels of mRNA and NF protein fall rapidly in the first week after axotomy and plateau (Tetzlaff, 1989) some time before the stabilization of CAP amplitude and fiber diameter 3 months later (Fig. 8; Davis et al., 1978). The final axonal size may very well reflect the final equilibrated axonal content of neurofilaments.

\section{Stimulation and atrophy}

Chronic stimulation of axotomized nerves during the first month had a small but significant effect in reducing the atrophy of the largest fibers. The effect was not detected by electrophysiological recording of the CAP, which showed $\sim 50 \%$ fall in CAP amplitude and $25 \%$ increase in latency for both stimulated and unstimulated nerves. To the extent that larger fibers dominate the latency of the positive peak of the CAP, the finding that there was no difference between the latency in the stimulated and unstimulated nerves can be explained by the sufficient number of large fibers in each. The fact that the amplitude was not changed is more surprising and would require more extensive morphological study of the nerves at these early times to firmly establish whether chronic stimulation of axotomized nerves delays the atrophy.

It is the larger fibers that are the most severely affected by axotomy (Fig. 7; Milner et al., 1981; Dyck et al., 1985) and whose atrophy appears to be slightly reduced by stimulation in the first month. These fibers include the mechanosensory and motor fibers, both of which undergo a dramatic reduction of neural activity following axotomy because of isolation from the sense organs and synaptic dysjunction, respectively (Gordon et al., 1980). The small early positive effect of chronic stimulation suggests that the normal decline in activity may contribute to the atrophy of axotomized nerves. If, as suggested above, the early atrophy can be attributed to localized changes in the cytoskeleton of axotomized nerves, it is possible that conduction of action potentials reduces the impact of local factors on axon caliber. Support for this idea comes from regeneration studies showing that $A C$ and $D C$ electrical stimulation can accelerate outgrowth of neural sprouts from the cut end of the axon, possibly by rcducing the injury current and thereby the latent period for sprouting (Hines et al., 1945; Gutmann and Jakoubek, 1963; Borgens, 1982; Nix and Hopf, 1983; Pockett and Gavin, 1985; McDevitt et al., 1987; Pomeranz, 1986).

Neural activity declines concurrently with fiber diameter and levels off in motoneurons at approximately $20 \%$ of normal levels at the time when fiber sizes stabilize at their lower values (Gordon et al., 1980). If neural activity was maintained for long periods by chronic stimulation, axotomized nerves atrophied more than they would have if their activity had declined normally (Figs. 8, 9). Perhaps the normal decline in neural activity of axotomized neurons is important for maintaining the neurons until peripheral contacts are remade, particularly as fibers may remain stable for long periods of time until they can remake functional connections (Davis et al., 1978). Activation of the atrophied nerves may promote breakdown of cytoskeletal protcins possibly by increasing free $\mathrm{Ca}$ levels or affecting other local processes in the nerves. Another possibility is that activity of the cells may downregulate NF protein even further than normal in a manner analogous to the response of axotomized nerves to 


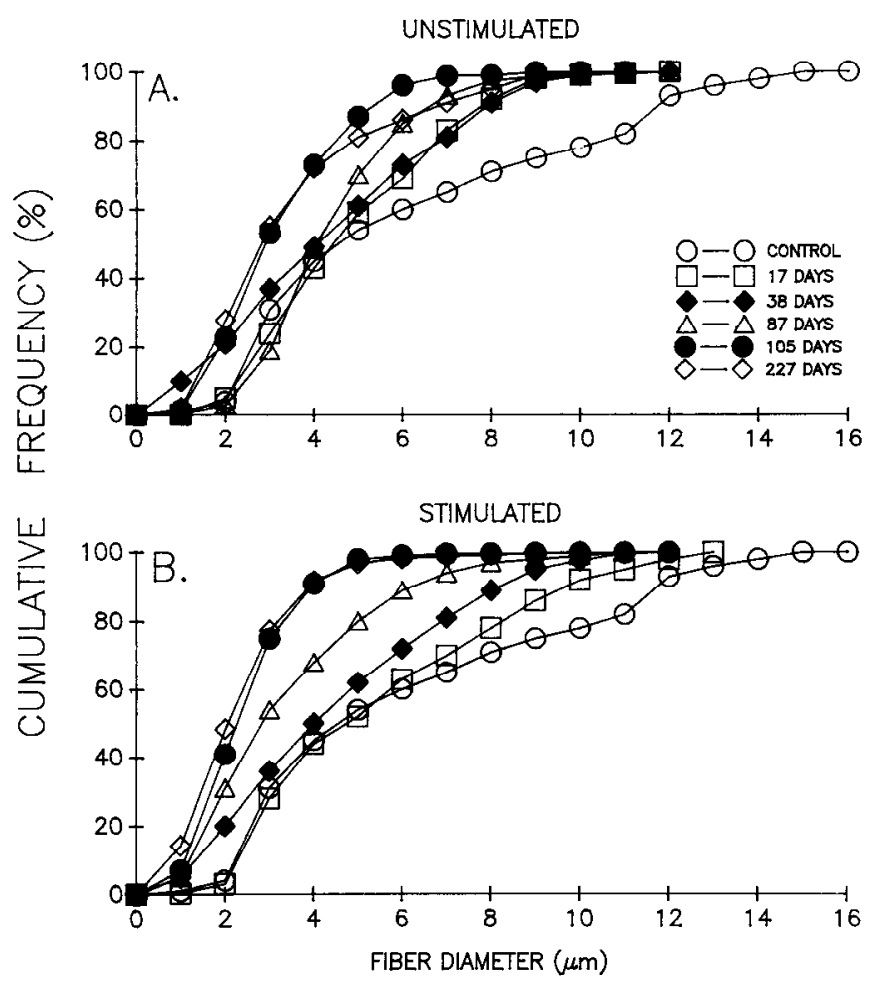

Figure 12. Comparison of the leftward shift of the cumulative frequency histograms for $(A)$ unstimulated and $(B)$ stimulated axotomized $\mathrm{CP}$ nerves at progressively longer times after axotomy. The fiber diameters of axotomized nerves were significantly smaller than normal at all time periods $(p<0.01)$. The leftward shift was more gradual in the stimulated axotomized nerves ( $B$; see also Fig. 8). Whether or not the nerves were stimulated, the axotomized nerve fibers did not continue to atrophy after $105 \mathrm{~d}$; the cumulative histograms for nerves 105 and $227 \mathrm{~d}$ after axotomy were not significantly different in either $(A)$ unstimulated or $(B)$ stimulated axotomized nerves, consistent with the stabilization of CAP amplitude and latency shown in Figures 4 and 5.

a second lesion, which has been shown to result in a significant further decline in NF expression (Tetzlaff, 1989). It is important to recognize that the chronic stimulation of the peripheral nerves is likely to activate the cell body retrogradely rather than by reflex activation because of the comparatively small contribution of monosynaptic inputs to synaptic activation of the flexor motoneurons and because the synaptic efficacy is reduced by synaptic dysjunction after axotomy (Mendell et al., 1976; reviewed by Gordon, 1983; Titmus and Faber, 1990). As a result, the effects of chronic stimulation are likely to reflect the abnormally high numbers of action potentials that are conducted in the axotomized nerves, which, under natural conditions, are relatively quiescent (Gordon et al., 1980). Whether anterograde activation of axotomized nerves would have a similar effect is not clear at this time but may be tested experimentally.

\section{Conclusions}

The finding that imposing chronic stimulation on axotomized nerves failed to reduce or reverse the decline in fiber size, in contrast to the complete recovery of fiber size if the nerves regenerate and remake functional connections (Gordon and Stein, 1982), shows that neural activity is unlikely to play a major role in the normal maintenance of nerve fiber caliber and thus control of gene expression for cytoskeletal proteins. Nevertheless, there is evidence that when neuromuscular connections remain intact, activity can modulate the trophic effect since quiescent motor nerves after spinal isolation and deafferentation have been found to increase in diameter (Gordon et al., 1989). Thus, the combination of these and other studies shows that the major trophic control of nerve fiber size is mediated by functional contacts with peripheral targets and that neural activity plays a relatively small role. In the absence of functional contacts, nerve fibers decline in diameter to stable but lower values.

Nonetheless, activity may modulate the response of the cell to axotomy. Decline in activity during the first month may promote the downregulation of NF protein as part of the response of the cell to loss of trophic regulation, and reduced activation of axotomized nerves could be an important factor in their maintenance until the damaged nerves regenerate and make functional connections with peripheral targets.

\section{References}

Aitken JT, Thomas PK (1962) Retrograde changes in fiber size following nerve section. J Anat 96:121-129.

Aldskogius H, Risling M (1981) Effect of sciatic neurectomy on neuronal number and size distribution in the $\mathbf{L} 7$ ganglion of kitten. Exp Neurol 74:597-604.

Anderson Y, Edstrom J (1957) Motor hyperactivity resulting in diameter decrease of peripheral nerves. Acta Physiol Scand 39:240245.

Borgens RB (1982) What is the role of naturally produced electric current in vertebrate regeneration and healing? Int Rev Cytol 76:245298.

Carlson J, Lais AC, Dyck PJ (1979) Axonal atrophy from pcrmanent peripheral axotomy in adult cat. J Neuropath Exp Neurol 38:579585.

Cragg BG, Thomas PK (1961) Changes in conduction velocity and fibre size proximal to peripheral nerve lesions. J Physiol (Lond) 157: 315-327.

Czeh G, Gallego R, Kudo N, Kuno M (1978) Evidence for the maintenance of motoneurone properties by muscle activity. J Physiol (Lond) 281:239-252.

Davis LA, Gordon T, Hoffer JA, Jhamandas J, Stein RB (1978) Compound action potentials recorded from mammalian peripheral nerves following ligation or resuturing. J Physiol (Lond) 143:543-559.

Dyck PJ, Lais AC, Karnes JL, Sparks M, Huner H, Low PA, Winderbank AJ (1981) Permanent axotomy, a model of axonal atrophy and secondary segmental demyclination and remyclination. Ann Neurol 9:575-583.

Dyck PJ, Lais A, Karnes J, Sparks M, Dyck PJB (1985) Peripheral axotomy induces neurofilament decrease, atrophy, demyelination and degeneration of root and fasciculus gracilis fibers. Brain Res 340:1936.

Edds MV (1949) Experiments on partially deneurotized nerves. J Exp Zool 112:29-47.

Edds MV (1950) Hypertrophy of nerve fibers to functionally overloaded muscles. J Comp Neurol 93:259-275.

Eisen AA, Carpenter S, Karpati G, Bellavance A (1973) The effects of muscle hyper- and hypoactivity upon fiber diameters of intact and regenerating nerves. J Neurol Sci 20:457-469.

Fisz M (1963) Probability and mathematical statistics. New York: Wilcy.

Foehring RC, Sypert GW, Munson JB (1986) Properties of self-reinnervated motor units of medial gastrocnemius of cat. II. Axotomized motoneurons and time course of recovery. J Neurophysiol 55:947965.

Friede R, Samorajski T (1970) Axon caliber related to neurofilaments and microtubules in sciatic nerve fibers of rats and mice. Anat Rec 167:379-387.

Gallego R, Kuno M, Nunez R, Snider WD (1979) Dependence of motoneurone properties on the length of immobilized muscle. J Physiol (Lond) 291:179-189.

Gillespie MJ, Stein RB (1983) The relationship between axon diameter, myelin thickness and conduction velocity during atrophy in mammalian peripheral nerves. Brain Res 259:41-56.

Gordon T (1983) Dependence of peripheral nerves on their target organs. In: Somatic and autonomic nerve-muscle interactions (Burn- 
stock G, Vrbova G, O’Brien R, eds), pp 289-325. Amsterdam: Elsevier.

Gordon T, Stein RB (1982) Time course and extent of recovery in reinnervated motor units of cat triceps surae muscle. J Physiol (Lond) 323:307-323.

Gordon T, Hoffer JA, Jhamandas J, Stein RB (1980) Long-term effects of axotomy on neural activity during cat locomotion. J Physiol (Lond) 303:243-264

Gordon T, Kelly MEM, Sanders EJ, Shapiro J, Smith PA (1987) The effects of axotomy on bullfrog sympathetic neurones. J Physiol (Lond) 392:213-229.

Gordon T, Aurora S, Eldridge L (1989) Anterograde regulation of the calibre of motor nerves. Can J Physiol Pharmacol 49:A14.

Grafstein B, McQuarrie IG (1978) Role of the nerve cell body in axonal regeneration. In: Neuronal plasticity (Cotman CW, ed), pp 155-195. New York: Raven.

Grainger F, Sloper JC (1976) Microtubular number in the tractus hypophyseus of newborn normal rats and newborn rats with congenital diabetes insipidus. Cell Tissue Res 169:405-414.

Greenberg SG, Lasek RJ (1988) Neurofilament protein synthesis in DRG neurons decreases more after peripheral axotomy than after central axotomy. J Neurosci 8:1789-1796.

Gustafsson B, Pinter MJ (1984) Effects of axotomy on the distribution of passive electrical properties of cat motoneurones. J Physiol (Lond) 356:433-442.

Gutmann E, Jakoubek B (1963) Effect of increased motor activity on regeneration of peripheral nerve in young rats. Physiol Bohemoslov $12: 463-468$

Gutmann E, Sanders FK (1943) Recovery of fibre numbers and diameters in the regeneration of peripheral nerves. J Physiol (Lond) 101:489-518.

Hall ME, Wilson DL, Stone GC (1978) Changes in synthesis of specific proteins following axotomy: detection with two-dimensional gel electrophoresis. J Neurobiol 9:454-466.

Heacock AM, Agranoff BW (1976) Enhanced labeling of a retinal protein during regeneration of optic nerve in goldfish. Proc Natl Acad Sci USA 73:828-832.

Hines H, Melville E, Wehrmacher W (1945) The effect of electrical stimulation on neuromuscular regeneration. Am J Physiol 144:278283.

Hoffer JA, Stein RB, Gordon T (1979) Differential atrophy of sensory and motor fibres following section of cat peripheral nerves. Brain Res 178:347-361.

Ioffman PN (1988) Distinct roles of neurofilament and tubulin gene expression in axonal growth. In: Plasticity of the neuromuscular system, CIBA foundation symposium, Vol 138, pp 192-204. Chichester Wiley.

Hoffman PN (1989) Expression of GAP43, a rapidly transported growth-associated protein, and Class II beta tubulin, a slowly transported cytoskeletal protein, are coordinated in regenerating neurons. J Neurosci 9:893-897.

Hoffman PN, Lasek RJ (1975) The slow component of axonal transport: identification of major structural polypeptides of the axon and their generality among mammalian neurons. J Cell Biol 66:351-366.

Hoffman PN, Lasek RJ (1980) Axonal transport of the cytoskeleton in regenerating motor neurons: constancy and change. Brain Res 202: 317-333.

Hoffman PN, Thompson GW, Griffin JW, Price DL (1983) Changes in neurofilament transport coincide temporally with alterations in the caliber of axons in regenerating motor fibers. J Cell Biol 101:13321340.

Hoffman PN, Griffen JW, Price DL (1984) Control of axonal caliber by neurofilament transport. J Cell Biol 99:705-714.

Hoffman PN, Cleveland DW, Griffin JW, Landes PW, Cowan NJ, Price DL (1987) Neurofilament gene expression: a major determinant of axon caliber. Proc Natl Acad Sci USA 84:3472-3476.

Kalil K, Skene JHP (1986) Elevated synthesis of an axonally transported protein correlates with axon outgrowth in normal and injured pyramidal tracts. J Neurosci 6:2563-2570.

Kelly MEM, Traynor P, Smith PA (1989) Amphibian sympathetic ganglia as a model system for investigating regeneration in the vertebrate peripheral nervous system. Comp Biochem Physiol 93A:133140.

Kreutzberg GW, Schubert P (1971) Volume changes in axons during regeneration. Acta Neuropathol 17:220-226.

Kuno M, Miyata Y, Munoz-Martinez EJ (1974) Differential reactions of fast and slow alpha-motoneurones to axotomy. J Physiol (Lond) 240:725-739.

Liebermann AR (1971) The axon reaction: a review of the principal features of perikayal responses to axon injury. Int Rev Neurobiol 14 49-124.

Lubinska $L$ (1961) Demyelination and remyelination in the proximal parts of regenerating nerve fibres. J Comp Neurol 117:275-289.

Lutt AR, Hatcher DD, Torkko K (1988) Enlarged motor units resulting from partial denervation of cat hindlimb muscles. J Neurophysiol 59 : 1377-1394.

McDevitt L, Fortner P, Pomeranz B (1987) Application of weak electric field to the hindpaw enhances sciatic motor nerve regeneration in the adult rat. Brain Res 416:308-314.

Mendell LM, Munson JB, Scott JG (1976) Alterations of synapses on axotomised motoneurones. J Physiol (Lond) 255:57-79

Milncr TE, Stein RB (1981) The effects of axotomy on the conduction of action potentials in peripheral sensory and motor nerve fibres. $J$ Neurol Neurosurg Psychiatry 44:476-484.

Milner TE, Stein RB, Gillespie J, Hanley B (1981) Improved estimates of conduction velocity distributions using single unit action potentials J Neurol Neurosurg Psychiatry 44:476-484.

Neumann D, Scherson T, Ginzburg I, Littauer UZ, Schwartz M (1983) Regulation of mRNA levels for microtubule proteins during nerve regeneration. FEBS Lett 162:270-276.

Nissl F (1892) Uber die Veraenderungen de Ganglienzellen am Facialiskern des Karinchens nach Ausreissung der Nerven. Allg Z Psychiat 48:197-198.

Nix WA, Hopf HC (1983) Electrical stimulation of regenerating nerve and its effect on motor recovery. Brain Res 272:21-25.

Oppenheim RW, Haverkamp LJ (1988) Neurotrophic interactions in the development of spinal cord motoneurons. In: Plasticity of the neuromuscular system, CIBA foundation symposium, Vol 138, pp 152-171. New York: Wiley.

Pinter MJ, Vanden Noven S, Muccio D, Wallace NL (1991) Axotomylike changes in cat motoneuron electrical properties elicited by botulinum toxin depend on the complete elimination of neuromuscular transmission. J Neurosci 11:657-666.

Pockett S, Gavin R (1985) Acceleration of peripheral nerve regeneration after crush injury in the rat. Neurosci Lett 59:221-224.

Pomeranz B (1986) Effects of applied DC fields on sensory nerve sprouting and motor nerve regeneration in adult rats. Prog Clin Biol Res 210:251-260.

Purves D (1975) Functional and structural changes of mammalian sympathetic neurones following interruption of their axons. J Physiol (Lond) 252:429-463.

Risling M, Aldskogius J, Hildebrand C, Remahl SL (1983) Effects of sciatic nerve resection on $\mathrm{L} 7$ spinal roots and dorsal root ganglia in adult cats. Exp Neurol 82:568-580.

Roy RR, Gilliam TB, Taylor JF, Heusner WW (1984) Activity-induced morphologic changes in rat soleus nerve. Exp Neurol 80:622632 .

Sinicropi DV, McIlwain DL (1983) Changes in the amounts of cytoskeletal proteins within the perikarya and axons of regenerating frog motoneurons. J Cell Biol 96:240-247.

Skene JHP (1989) Axonal growth-associated proteins. Annu Rcv Neurosci $12: 127-156$.

Skene JHP, Willard M (1981) Axonally transported proteins associated with axon growth in rabbit central and peripheral nervous systems. J Cell Biol 89:96-103.

Somorajski T, Rolsten C (1975) Nerve fiber hypertrophy in posterior tibial nerves of mice in response to voluntary running activity during aging. J Comp Neurol 159:553-558.

Spencer PS, Thomas PK (1970) The examination of isolated nerve fibres by light and electron microscopy with observations on demyelination proximal to neuromas. Acta Neuropathol 16:177-186.

Stein RB, Charles D, Davis L, Jhamandas J, Mannard A, Nichols TR (1975) Principles underlying new methods for chronic neural recording. Can J Neurol Sci 2:235-244.

Stein RB, Nichols TR, Jhamandas J, Davis L, Charles D (1977) Stable long-term recordings from cat peripheral nerves. Brain Res 128:2138.

Tetzlaff W (1989) Expression of cyloskeletal genes in axotomized neurons of the peripheral and central nervous system. PhD thesis, University of Calgary, Alberta.

Tetzlaff W, Bisby MA (1989) Neurofilament elongation into regenerating facial nerve axons. Neuroscience 29:659-666. 
Tetzlaff W, Bisby MA, Kreutzberg GW (1988a) Changes in cytoskeletal proteins in the rat facial nucleus following axotomy. J Neurosci 9:914-922.

Tetzlaff W, Miller FD, Bisby MA (1988b) Synthesis of cytoskeletal proteins by axotomized and regenerating motoneurons. Curr Issues Neural Regeneration Res 48:13-22.

Tetzlaff W, Zwiers H, Lederis K, Cassar L, Bisby MA (1989) The axonal transport and localization of B50/GAP43-like immunoreactivity in regenerating sciatic facial nerves of the rat. J Neurosci 9: 1303-1313.

Titmus MJ, Faber DS (1990) Axotomy-induced alterations in the electrophysiological characteristics of neurons. Prog Neurobiol 35:151.

Verge VMK, Tetzlaff W, Bisby MA, Richardson PM (1990) Influence of nerve growth factor on neurofilament gene expression in mature primary sensory neurons. J Neurosci 10:2018-2025.

Voyvodic JT (1989) Target size regulates calibre and myelination of sympathetic axons. Nature 342:430-433.

Wong J, Oblinger MM (1987) Changes in neurofilament gene expression occur after axotomy in dorsal root ganglion neurons: an in situ hybridization study. Metab Brain Dis 2:291-303.

Woolf CJ, Chong MS, Ainsworth A (1984) Axotomy increases glycogen phosphorylase activity in motoneurons. Neuroscience 12:12611269.

Young JZ (1950) The determination of the specific characteristics of nerve fibers. In: International conference on the development, growth and regeneration of the nervous system: genetic neurology (Weiss $P$, ed), pp 92-104. Chicago: University of Chicago Press. 